\title{
Influence of Process Parameters on Aluminium Alloy 6061-O Joints by Friction Stir Welding Process
}

\author{
A. Varun Kumar and M. Balasrinivasan
}

\begin{abstract}
The present work reports the influence of process parameters (tool speed, traverse speed and axial load) on the metallurgical and mechanical properties of joints fabricated by friction stir welding process. The samples were friction stir welded under tool rotational speed of 1120, 1250 \& $1500 \mathrm{rpm}$ and traversing speed of $0.5,0.6 \& 0.8 \mathrm{~mm} / \mathrm{sec}$ with an axial load of $9000 \mathrm{Kg}$ constant for all the trials. Single pass friction stir welding process was followed in this investigation. Metallographic analysis was carried out across various zones of weldments (Unaffected Base Metal, Heat Affected Zone, Thermo Mechanically Affected Zone and Nugget Zone). Mechanical tests (microhardness survey \& tensile test) were evaluated and all the results were correlated with the parent base metal. For better understanding scanning electron microscope (SEM) analysis was carried out in the nugget zone to predict the flow of materials due to severe stirring process. It is observed from the results that joint fabricated with a tool speed of $1250 \mathrm{rpm}$, traverse speed of 0.8 $\mathrm{mm} / \mathrm{sec}$ and axial load of $9000 \mathrm{Kg}$ showed a defect free joint, with better refined grain structures and high tensile strength when compared to all other trials done.
\end{abstract}

Keywords--- Friction Stir Welding (FSW), Single Pass Welding Process, Metallographic Analysis, Microhardness Test, Tensile Test and Scanning Electron Microscope(SEM) Analysis

\section{INTRODUCTION}

A LUMINIUM alloys are widely used in various applications around the automotive and aircraft industries because of their light weight properties, better corrosion resistant and high strength to weight ratio. Different welding processes were available for welding light weight alloys among this friction stir welding process is more compatible when compared to other fusion welding processes due to better weld quality [1]. Friction stir welding process is a solid state welding process in which the joint is produced between two alloys both similar and dissimilar [2]. The welding process is carried by means of friction between the parent material and tool, due to a severe stirring process the material gets plasticised and movement takes place from the retreating side to advancing side, the various zones of FSW process can be classified as nugget zone [NZ], heat affected zone [HAZ], thermo mechanically affected zone [TMAZ] and unaffected base metal [UA] on both retreating and advancing sides [3]. Similarly the weldment strength can also varied by the tool pin design such as threaded, square, plain cylindrical, etc., [4]. There are lot of works been carried out with different combinations of process parameters in the friction stir welding process. So we considered to produce joints between two similar aluminium alloy by varying only the tool speed and traverse speed with the axial load as constant for all the joints. Main factor is to determine the impact of these two process parameters on the fabricated joint. Similarly few works has been conducted with double pass either multi pass of tool material over the parent metal [5-6], here we tried to produce the joints by a single pass friction stir welding process in order to reduce the time factor to produce a joint and also to check the reliability of the joints made by single pass friction stir welding process by conducting metallurgical analysis across various zones of the weldments and mechanical test (tensile test \& microhardness test).

\section{EXPERIMENTAL PROCEDURE}

\section{A. Materials Used}

The materials used in this work are AA 6061-O (150 x $100 \times 6 \mathrm{~mm}$ ) and high carbon steel D3 (hardened to 58-60 HRC) as tool used for stirring process, dimensions of the tool are rod diameter $20 \mathrm{~mm}$, shoulder diameter $15 \mathrm{~mm}$, pin probe length $5.7 \mathrm{~mm}$, pin diameter $5.7 \mathrm{~mm}$ (pin used is a straight flat cylindrical type). The shoulder of the tool is tilted to $2^{\circ}$ for better movement of material from retreating side to the advancing side. The material properties of material and tool were listed in table $1 \& 2$. The process parameter used in this experiment is listed in table 3 . The set up was made as per the requirement and the joints were produced by varying the tool speed, traverse speed and axial load of $9000 \mathrm{Kg}$ constant for all the trials.

A. Varun Kumar, Assistant Professor, Department of Mechanical Engineering, B. S Abdur Rahman University, Chennai-600 048, India. E-mail: varunkumar.aec@gmail.com

M. Balasrinivasan, Assistant Professor, Department of Mechanical Engineering, B. S Abdur Rahman University, Chennai-600 048, India. E-mail: balasrnvsn@gmail.com

DOI: 10.9756/BIJIEMS.8065 
Table 1: Chemical Compositions of AA 6061-O in (Wt \%), [7]

\begin{tabular}{|l|l|l|l|l|l|l|l|l|l|}
\hline Elements & $\mathrm{Al}$ & $\mathrm{Cr}$ & $\mathrm{Cu}$ & $\mathrm{Fe}$ & $\mathrm{Mg}$ & $\mathrm{Mn}$ & $\mathrm{Si}$ & $\mathrm{Ti}$ & $\mathrm{Zn}$ \\
\hline Composition & $95.8-98.6$ & $0.04-0.35$ & $0.1-0.4$ & 0.7 & $0.8-1.2$ & 0.15 & $0.4-0.8$ & 0.15 & 0.25 \\
\hline
\end{tabular}

Table 2: Chemical Compositions of High Carbon Steel D3 in (Wt\%), [8]

\begin{tabular}{|c|c|c|c|c|c|}
\hline Elements & $\mathrm{C}$ & $\mathrm{Si}$ & $\mathrm{Mn}$ & $\mathrm{Cr}$ & $\mathrm{V}$ \\
\hline Composition & 2.15 & 0.40 & 0.40 & 12.25 & 0.25 \\
\hline
\end{tabular}

Table 3: Process Parameter Response Table

\begin{tabular}{|c|c|c|}
\hline Experiments (Samples) & $\begin{array}{c}\text { Tool Speed } \\
(\mathrm{rpm})\end{array}$ & $\begin{array}{c}\text { Traverse Speed } \\
(\mathrm{mm} / \mathrm{sec})\end{array}$ \\
\hline 1 & 1120 & 0.5 \\
\hline 2 & 1120 & 0.6 \\
\hline 3 & 1120 & 0.8 \\
\hline 4 & 1250 & 0.5 \\
\hline 5 & 1250 & 0.6 \\
\hline 6 & 1250 & 0.8 \\
\hline 7 & 1500 & 0.5 \\
\hline 8 & 1500 & 0.6 \\
\hline 9 & 1500 & 0.8 \\
\hline
\end{tabular}

\section{RESULTS AND DisCUSSIONS}

\section{A. Metallographic Analysis}

All the samples were friction stir welded under different tool and traverse speed. Samples were polished and etched using Keller's reagent which is most suitable for all the aluminium alloys. Optical microstructures were observed for sample number 6 across various zones based on the tensile results obtained (Unaffected base metal, heat affected zone, thermo mechanically affected zone and nugget zone) both retreating and advancing sides. Figure 1(a) shows base metal microstructure with equiaxed grains, with relatively uniform grain structures [9-10]. It is also inferred from the NZ figure. 1 (d) refined formation of grains due to stirring process across the weld bond, considerably correlating the TMAZ zone on both sides figure. 1 (e \& f) that there is an increase in grain structure which leads to deterioration of tensile properties [11]. From figure. $1(\mathrm{~g} \& \mathrm{~h}$ ) the HAZ grains were less recrystallized to that of TMAZ zone, similarly material flow from the advancing side to retreating side can be seen from figure. 1(e). Compared to the base metal the unaffected base metal of welded sample showed less equiaxed grains due to heat generation during the process figure. 1(b \& c). Correlating the metallurgical properties of weldments (various zones) with base metal it resulted in better refined grain structures due to material transfer and plasticisation in the friction stir welding process.



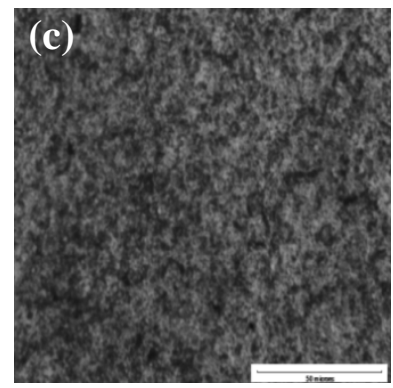
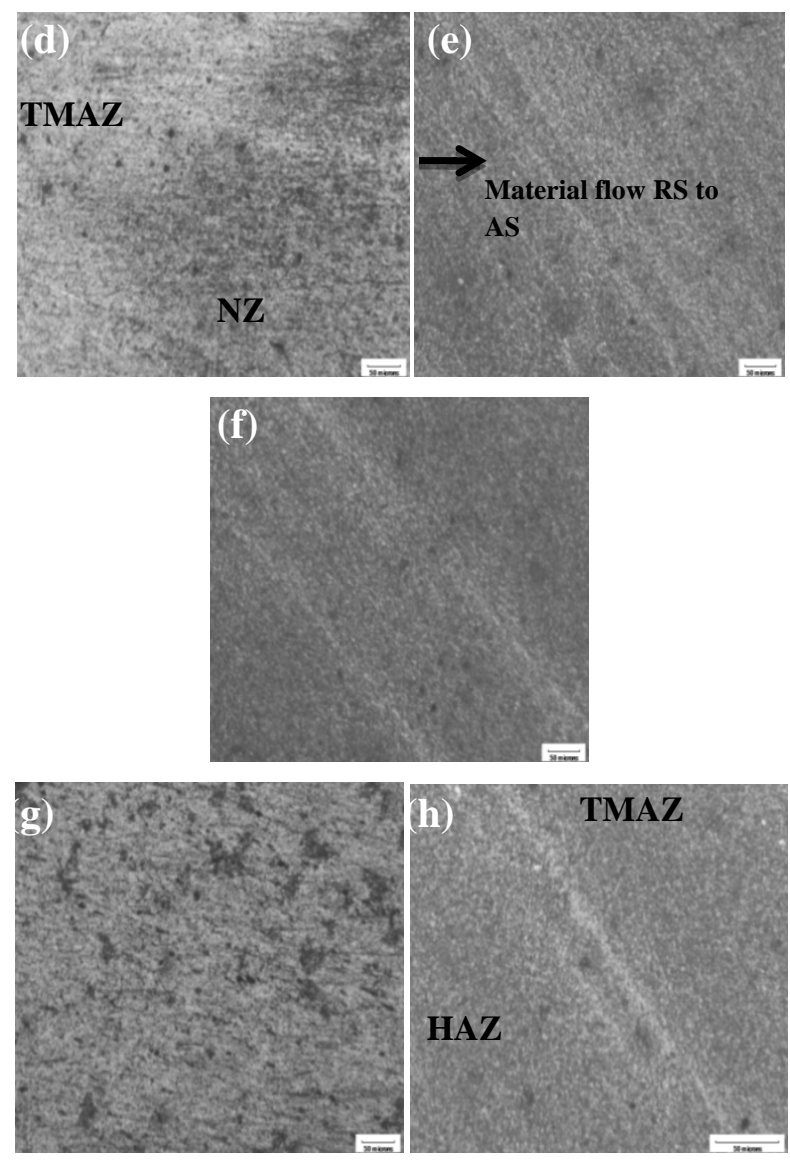

Figure 1: Optical Microstructures of Sample Number 6 - (a) Base Metal, (b) UA Base Metal - AS, (c) UA Base Metal RS, (d) NZ, (e) TMAZ - AS, (f) TMAZ - RS, (g) HAZ AS, (h) HAZ - RS

\section{B. Scanning Electron Microscope (SEM) Analysis}

Figure. 2 (a \& b) shows the (SEM) micrograph for sample number 6 with a tool speed of $1250 \mathrm{rpm}$, traverse speed of $0.8 \mathrm{~mm} / \mathrm{sec}$ and axial load of $9000 \mathrm{Kg}$. The scanning electron microscope test has been done in the nugget zone of the friction stir welded sample in order to predict the flow of materials from the retreating side to advancing side due to severe stirring process that takes place with the contact of pin probe in the weld bond length. From the figure it can be clearly seen that pattern of flow from the retreating to advancing side of the alloy with no voids and cracks. Figure. 2 (b) shows the presence of 
silicon ( $\mathrm{Si}$ ) in the nugget zone. Also the grains boundaries and structure were well refined in the nugget zone due to the stirring process, better plasticization of aluminium alloy which shows the good fusion had happened in the nugget zone as reported by [12]. Figure. 2 (a \& b) reveals that a strong stirring action had occurred in the nugget zone region as discussed by [13].

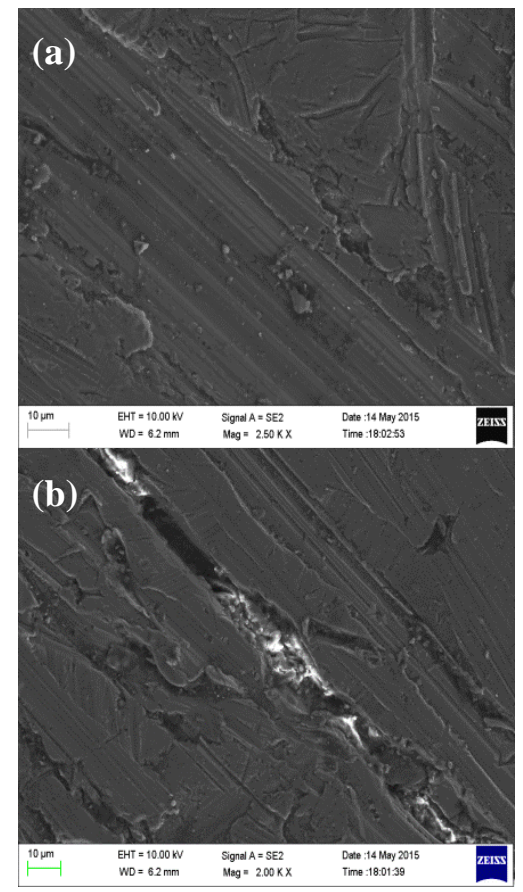

Figure 2: SEM Micrograph of Sample Number 6 - (a \& b) Nugget Zone

\section{Tensile Properties}

The ultimate tensile strength (UTS) for the weldments was evaluated using a tensile testing machine figure. 3 shows the tensile properties profile of weldments all the samples were prepared as per (ASTM E08) standard for testing. Compared to the base metal, friction stir welded samples showed better tensile properties due to the stirring process and plasticization of material. The UTS value is increased with the increase in traverse speed which results in defect free joint and better UTS value to that of base metal, further increase in traverse speed resulted in decreased UTS value [14]. UTS values were listed in table 4.



Figure 3: Tensile Properties of Welded Samples
Table 4: Tensile Properties of Friction Stir Welded AA 6061-O

\begin{tabular}{|c|c|c|}
\hline $\begin{array}{c}\text { Experiments } \\
\text { (Samples) }\end{array}$ & $\begin{array}{c}\text { Experimental UTS } \\
\text { (Newton) }\end{array}$ & $\begin{array}{c}\text { Percentage Elongation } \\
\text { (mm) }\end{array}$ \\
\hline 1 & 2112 & $2.02 \pm 0.2$ \\
\hline 2 & 3562.5 & $3.42 \pm 0.2$ \\
\hline 3 & 1637.5 & $2.95 \pm 0.2$ \\
\hline 4 & 3162.5 & $3.05 \pm 0.2$ \\
\hline 5 & 4512 & $3.66 \pm 0.2$ \\
\hline 6 & 4887 & $4.51 \pm 0.2$ \\
\hline 7 & 3637.5 & $3.97 \pm 0.2$ \\
\hline 8 & 1962.5 & $2.36 \pm 0.2$ \\
\hline 9 & 2725 & $2.25 \pm 0.2$ \\
\hline
\end{tabular}

\section{Microhardness test}

Figure 4. shows the microhardness profile for the welded samples. Base metal has a $40 \mu \mathrm{HV}$ microhardness value [15]; compared to the base metal the welded samples resulted in better hardness property due to material movement. In the present experiment the failure occurred in TMAZ zone which is very adjacent to weld nugget which resulted in higher hardness value in the nugget zone [16]. Also from graph it is inferred that hardness values were similar in the TMAZ and HAZ zone both retreating as well advancing side due to plasticization of material. The UA base metal showed some deviations in the hardness value when compared to the base metal due heat transfer from the adjacent zones of the weldments.

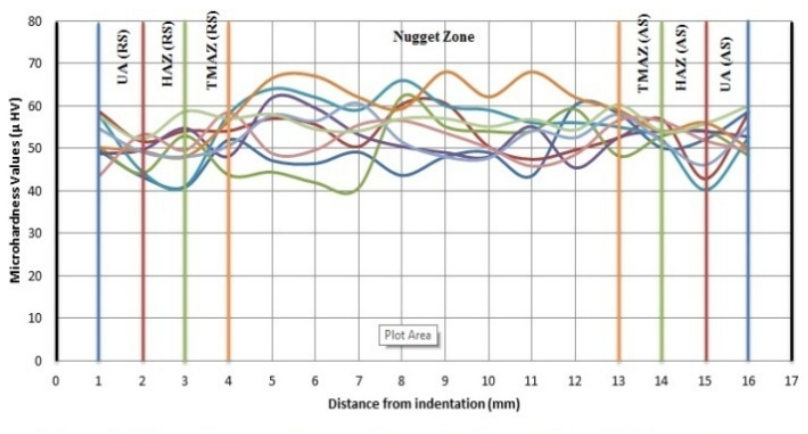

Figure 4: Microhardness Profiles of Welded Samples

\section{CONCLUSION}

In the present work influence of process parameters on fabricated joints of aluminium alloy 6061-O was evaluated and the following conclusions were made

- Successful joints were made on similar aluminium alloy $6061-O$ by friction stir welding process.

- Metallurgical survey were carried on parent base metal and across the various zones of weldments (UA base metal, TMAZ, HAZ, NZ) on both retreating \& advancing sides.

- $\quad$ SEM results revealed a better flow of materials in the nugget zone with no voids which shows a defect free joint.

- Tensile strength of the weldments showed a better result to that of base metal. 
- Microhardness values showed better enhancement when correlated with base metal.

- Nugget zone plays a vital role in friction stir welding process, because the bonding of material either a similar or dissimilar alloys can be made successful only with the refined grain boundaries at the nugget zone.

- Comparing with the mechanical and metallurgical properties it is revealed that tool speed of $1250 \mathrm{rpm}$, traverse speed of $0.8 \mathrm{~mm} / \mathrm{sec}$ and axial load of 9000 $\mathrm{Kg}$ resulted in a defect free joint among all other parameters used in this work.

\section{ACKNOWLEDGMENT}

Authors thank the technical support of Mr. D. Murali Manohar (Assistant professor, Department of Polymer Technology, B. S Abdur Rahman University, Chennai) for helping us in carrying out the tensile test.

\section{REFERENCE}

[1] Jawdat A. Al-Jarrah, SallamehSwalha, Talal Abu Mansour, Masoud Ibrahim, Maen Al-Rashdan, Deya A. Al-Qashi, "Welding equality and mechanical properties of aluminium alloys joints prepared by friction stir welding”, Materials and Design, Vol 56, Pp 929-936, April 2014.

[2] Sadeesh P, Venkatesh Kannan M, Rajkumar V, Avinash P, Arivazhagan N, Devendranath, Ramkumar K, Narayanan S, "Studies on friction welding of AA 2024 and AA 6061 dissimilar metals", Procedia Engineering, Vol 75, Pp 145-149, 2014.

[3] A. Varun Kumar, K. Balachandar, "Effect of welding parameters on metallurgical properties of friction stir welded aluminium alloy 6063O”, Journal of Applied Sciences, Vol 12, Issue 12, Pp 1255-1264, 2012.

[4] Md. Reza-E-Rabby, Anthony P. Reynolds,"Effect of tool pin thread forms on friction stir weldability of different aluminium alloys", Procedia Engineering, Vol 90, Pp 637-642, 2014.

[5] N. Sun, D. Apelian: Friction stir processing of aluminium cast alloys for high performance applications, JOM, Vol. 63, Pp 44-50, 2011.

[6] M. Bharathi, P. Ganesh, "The influence of multi pass friction stir welding on the micro structural and mechanical properties of dissimilar aluminium alloys”, IOSR Journal of Mechanical and Civil Engineering, ISSN - 2278-1684, Vol 30, Issue 6, Pp 33-36, 2009.

[7] Metals Handbook - Properties and selection: Nonferrous alloys and special purpose materials, ASM International $10^{\text {th }}$ edition, Vol 2, 1990.

[8] Latrobe specialty steel company, LSS ${ }^{\mathrm{TM}} \mathrm{D} 3$ tool steel. Latrobe, PA USA, 2006

[9] D. M. Rodrigues, A. Loureiro, C. Leitao, R. M. Leal, B. M chaparro, P. Vilaca, "Influence of friction stir welding parameters on the microstructural and mechanical properties of AA 6016-T4 thin welds”, Materials and Design, Vol 30, Issue 6, Pp1913-1921,2009.

[10] K. TejonadhaBabu, P. Kranthi Kumar, S. Muthukumaran, "Mechanical, metallurgical and corrosion properties of friction stir welded AA 6061-T6 using commercial pure aluminium as a filler plate”, Procedia Material Science, Vol 6, Pp 648-655, 2014.

[11] Rajkumar V, Venkateshkannan. M, Sadeesh P, Arivazhagan N, Devendranath, Ramkumar K, "Studies on effect of tool design and welding parameters on the friction stir welding of dissimilar aluminium alloys AA 5052 - AA 6061”, Procedia Engineering, Vol 75, Pp 93-97, 2014.

[12] S. Ravikumar, V. Seshagiri Rao, R. V. Pranesh, "Effect of process parameters on mechanical properties of friction stir welded dissimilar materials between AA 6061-T651 and AA 7075-T651 alloys", International Journal of Mechanical Engineering, ISSN 2250-3234, Vol 4, No 1, Pp 101-114, 2014.

[13] Ki-Sang Bang, Kwang-Jin Lee, Han-Sur Bang, Hee-Sun Bang, "Interfacial microstructure and mechanical properties of dissimilar friction stir welds between 6061-T6 aluminium and Ti-6\% Al-4\% V alloys”, Vol. 52, No. 5, Pp 974-978, 2011.

[14] K. Kalaiselvan, N. Murugan, "Role of friction stir welding parameters on tensile strength of AA 6061- $\mathrm{B}_{4} \mathrm{C}$ composite joint", Transactions of Nonferrous Metals - Society of China, Vol 23, Issue 3, Pages 616-624, 2013.

[15] Venkatesh B. N, M. S Bhagyashekar, "Preliminary studies on mechanical metallurgical behaviour of friction stir welded joints", Procedia Engineering, Vol 97, Pp 847-85, 2014.

[16] H. J. Liu, J. C. Hou, H. Guo, "Effect of welding speed on microstructure and mechanical properties of self-reacting friction stir welded 6061-T6 aluminium alloy”, Materials and Design, Vol 50, Pp 872-878, 2013.

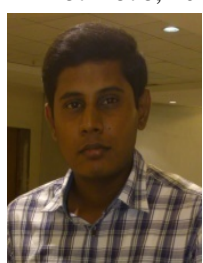

Varun Kumar A was born at Vellore on January 1988, He graduated in Mechanical Engineering with first class distinction from Arunai Engineering College, affiliated to Anna University, Chennai in 2009. He completed his master's degree in Advanced Manufacturing Technology from SASTRA University, Thanjavur in 2011. His research interest includes Solid State Welding Processes. $\mathrm{He}$ is currently working as Assistant Professor in the department of Mechanical Engineering at B. S. Abdur Rahman University, Chennai.

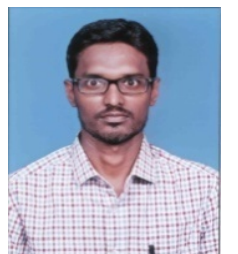

M. Balasrinivasan was born at Villupuram on February 1988, He graduated in Mechanical Engineering with first class distinction from Arunai Engineering College, affiliated to Anna University, Chennai in 2009. He completed his master's degree in Manufacturing Engineering from Madras Institute of Technology (MIT - An Autonomous Institution), Chennai in 2011. His research interest includes Solid State Welding Processes and simulation of welding processes. He is currently working as Assistant Professor in the department of Mechanical Engineering at B. S. Abdur Rahman University, Chennai. 